\title{
Questions toward a Peircean phenomenological description of association
}

Sørensen, Bent; Thellefsen, Torkild Leo

Published in:

Semiotica

DOI:

10.1515/sem-2015-0062

Publication date:

2015

Citation for published version (APA):

Sørensen, B., \& Thellefsen, T. L. (2015). Questions toward a Peircean phenomenological description of association. Semiotica, 207, 529-538. https://doi.org/10.1515/sem-2015-0062 


\title{
Bent Sørensen* and Torkild Thellefsen Questions toward a Peircean phenomenological description of association
}

DOI 10.1515/sem-2015-0062

\begin{abstract}
According to the philosopher and scientist Charles Peirce (1839-1914) phenomenology is fundamental to all scientific inquiry and association is the only force that exists within the intellect. However, Peirce only gave his reader a hint about the relationship between phenomenology and association. In this article we will try to follow that hint and point towards a couple of main questions that can guide a Peircean phenomenological description of association. Hence, the conclusion of the article will not be a phenomenological description of association but rather a couple of main questions trying to determine how such a phenomenological description can begin in the first place. Our hypothesis is that the questions depend for their construction on the inter-relatedness and interdependence of certain central Peircean phenomenological concepts - especially, Thirdness, Secondness, and Firstness.
\end{abstract}

Keywords: association, phenomenology, C. S. Peirce

$[\mathrm{N}]$ othing is truer than true poetry. And let me tell the scientific men that the artists are much finer and more accurate observers than they are, except of the special minutiae that the scientific man is looking for.

- Charles S. Peirce, Lectures on Pragmatism, 1903 (CP 1.315).

\section{Introduction}

According to the philosopher and natural scientist Charles Peirce (1839-1914) the act of association is: "the only force which exists within the intellect" (W 5: 326). Ideas are associated with each other through law or a tendency toward habit formation, hence: "There is a law in th[e] succession of ideas. We may roughly say that it is the law of habit. It is the great "Law of the Association of ideas" (CP 7.389). Peirce maintained that phenomenology is fundamental for all scientific

*Corresponding author: Bent Sørensen, Independent scholar, Denmark, E-mail: Legisign@gmail.com

Torkild Thellefsen, Copenhagen University, Copenhagen, Denmark, E-mail: thellefsen@gmail.com 
inquiry and he gave a hint about how to conceive association from a phenomenological perspective when he placed association in relation to the concept of medisense: "it has several varieties...the third [variety] is that of...association" (CP 7.544-50). The aim of this article is to follow that hint and to point towards a couple of main questions that can guide a Peircean phenomenological description of association. Hence, the conclusion of the article will not be a phenomenological description of association but rather a couple of main questions trying to determine how such a phenomenological description can begin in the first place. Our hypothesis is that the questions depend for their construction on the inter-relatedness and interdependence of certain central Peircean phenomenological concepts - especially, Thirdness, Secondness, and Firstness.

\section{Phenomenology - medisense, altersense, and feeling}

In order to get started, let us focus on some preliminary points of Peirce's science of phenomenology. According to Peirce, phenomenology is the first of the philosophical sciences. This means that in the architecture of his philosophical theory, phenomenology is the most fundamental science and its categories - of utter generality and centrality - are the most basic building blocks of the other philosophical sciences: aesthetics, ethics, logical, and metaphysics. Phenomenology contemplates phenomena as they are in order to discern the universal and necessary structures of consciousness. Having observed a very wide range of phenomena present to consciousness, Peirce came to the conclusion that there is a process of bringing to mind as a category of the phenomenon. Or, as Peirce wrote himself: "The removal of sensation from the department of cognition, or Knowledge, leaves nothing remaining in that department except what are called Mediate Cognitions, that is, Knowledges through some third idea or process different from either the Knowing self or the Known object” (CP 7.544). And then we have arrived where we started - at the concept of medisense - because as Peirce furthermore wrote: "All consciousness of a process belongs to this medisense” (CP 7.544). Hence, we can already ask the first - and most overall - question concerning a Peircean phenomenological description of association: 1) As a variety of medisense, how does association "bring something to mind"? Peirce himself did describe association as a variety of medisense in the following manner:

A great many associations of ideas are inherited. Others grow up spontaneously. The rest depend upon the principle that ideas once brought together into a set remain in that set. Many associations are merely accidental. A child acquires a distaste for a particular kind of 
food merely because it ate it when it was sick. The idea of that food and the feeling of sickness are brought into a set; and the consequence is that every time the idea of that food reaches a high degree of vividness, the feeling of sickness gets a swift upward motion. Other associations cannot be called accidental because it was in the nature of things that they should appear in sets. Thus, light and warm get associated in our minds because they are associated in Nature. (CP 7.550)

However, from the phenomenological perspective there must be more to it than if there indeed is "a great law of association" - and in the same paragraph Peirce did also say almost as an apology: "at present I hurry to the third form of medisense that of...association" (CP 7.550) - in an indirect way warning his reader that he would quickly leave the topic again. But how can we proceed from the paragraph in a systematic manner? Well, one way seems to be with Peirce understanding medisense as a part of a larger phenomenological system of concepts. First, Peirce said that consciousness forms a system and that medisense is related to two other categories, namely, feeling and altersense. According to Peirce, feeling and altersense can be defined in the following way: "Feeling is the momentarily present contents of consciousness taken in its pristine simplicity, apart from anything else. It is consciousness in its first state. Altersense is the consciousness of a directly present other or second, withstanding us" (CP 7.551).

But how is medisense related to altersense and feeling? Before we come to that, let us just mention how Peirce stressed that there are no other forms of consciousness than medisense, altersense, and feeling. This means that a Peircean phenomenological description of association, in principle, must not merely be regulatively valid, but must be definitive. Peirce advanced numerous arguments in favor of three and only three categories such as: "The fact that the minds of man have ever been inclined to threefold divisions is one of the considerations in favor of them" (CP 1.368). Coming back to how medisense is related to feeling and altersense, we just have to look at the word itself focusing on "medi," because according to Peirce this is exactly what this category of consciousness does - it mediates between feeling and altersense: "leading from the former to the latter" (CP 7.551). In the same paragraph, Peirce clarifies furthermore: "Feeling...is the consciousness of firstness; altersense is consciousness of otherness or secondness; medisense is the consciousness of means or Thirdness" (CP 7.551).

This description is of utmost centrality concerning our phenomenological questions regarding association, because here Peirce is making an explicit reference to the three concepts of Firstness, Secondness, and Thirdness in order to explain the three modes of consciousness. What is important for our purpose is that the three concepts according to Peirce are related in a certain hierarchical order. Peirce did argue for this hierarchy from different perspectives 
and by using different kinds of methods (also mathematical and relational logical) - here it will suffice to give an example from Peirce's research in logic from the article "On a New List of Categories" (1868):

I can discriminate red from blue, space from color, and color from space, but not red from color. I can prescind red from blue, and space from color (as is manifest from the fact that I actually believe there is an uncolored space between my face and the wall); but I cannot prescind color from space, nor red from color. I can dissociate red from blue, but not space from color, color from space, nor red from color. (CP 1.549)

In terms of the categories, it means that we can abstract Firstness from Secondness, but not vice versa. In the same manner, we can abstract Secondness from Thirdness, but not vice versa. Furthermore, the converse of this principle implies that Thirdness must involve Secondness as well as Firstness, and Secondness must involve Firstness. Finally, the principle also means that the categories "Firstness-Secondness-Thirdness" are organized in terms of increasing complexity. Hence, returning to our focus on association we can now deduce our second question concerning the phenomenological description of association: 2) In what way does association as a variety of medisense - or Thirdness - involve and mediate between altersense - or Secondness -as well as feeling - or Firstness? Put in another way: association involves altersense and feeling as necessary steps in the process of association. However, together they cannot fulfill the process without the conception of the Third in order to make association intelligible (Figure 1).

But with Peirce we find that things become even more complicated for at least two reasons: first, we remember that Peirce mentioned association as the third variety of medisense; hence, in addition to association he also described two other varieties termed abstraction and suggestion. Second, Peirce understood ideas as being attracted to one another by associational habits and dispositions associated by similarity, contiguity, and interest, respectively.

\section{Association, abstraction, and suggestion}

Concerning the first previously mentioned term: Peirce described the two other varieties of medisense - abstraction and suggestion - in the following manner:

In the first place there is a separative process, the centrifugal tendency of thought, by which any idea by following out its own development becomes separated from those with which it is connected. We see this in attention...I have spoken of the first kind of medisense, abstraction, which breaks one idea away from another. There is an opposite 


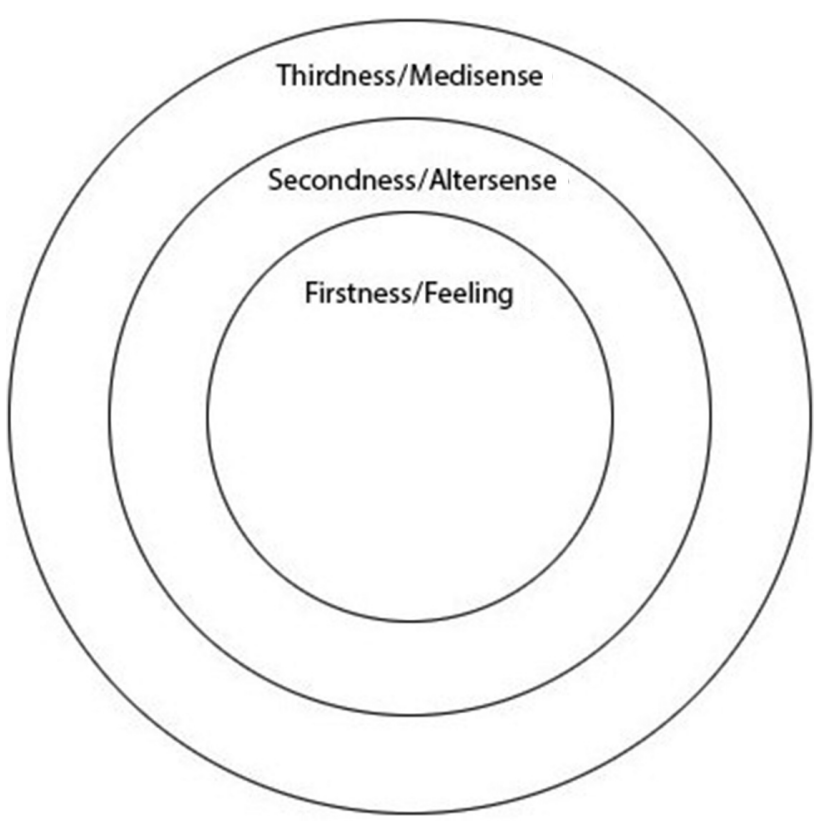

Figure 1: The phenomenological premises for our first and second question: the basic phenomenological hierarchy of inclusion and complexity.

influence by which when one idea has its vividness increased it gives an upward impulse to a number of other ideas with which it is connected so that it forms one set with them... I prefer the...English word suggestion. (CP 7.544-48)

So we must, somehow, also address the fact that association - as a variety of medisense - is related to two other varieties of medisense, in order to point towards questions that should be answered in a phenomenological description of association. But how shall we address this? Peirce said that association is the third variety of medisense and he also defined it after having first defined abstraction and suggestion. Therefore, we will follow Peirce's chronology when he defined the three varieties of medisense - first defining abstraction, then suggestion, and finally association - and understand abstraction, suggestion, and association as a continuum of increasing complexity. Or put another way: association is a Third also involving the two other varieties of medisense: suggestion and abstraction. Hence, we can now deduce our third question concerning the phenomenological description of association: 3) Being a Third of medisense, how does association involve and mediate between suggestion as well as abstraction respectively? (Figure 2). 


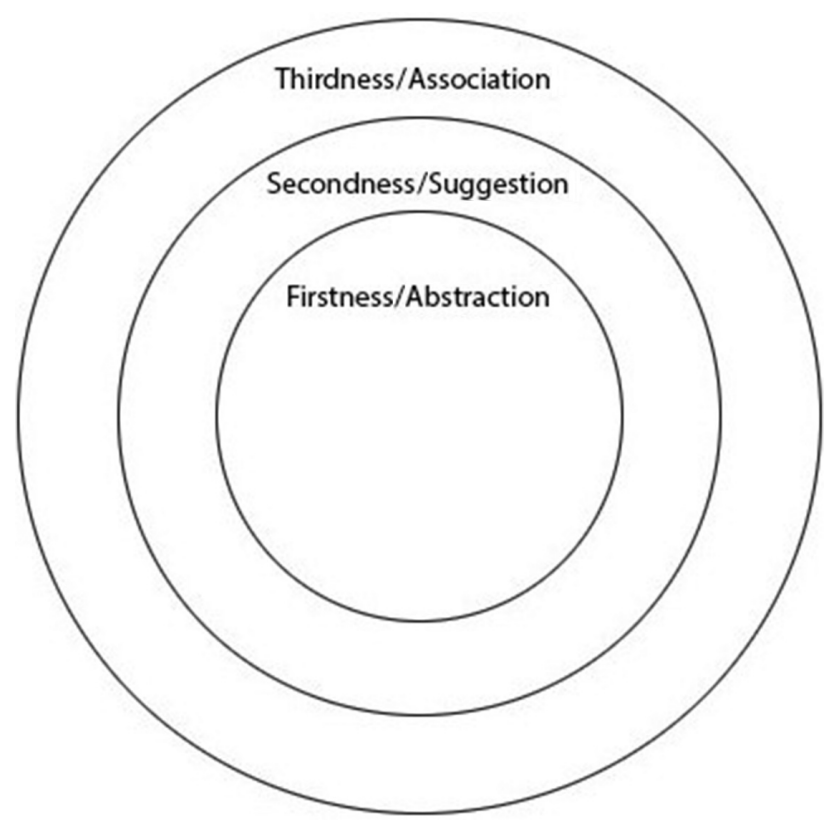

Figure 2: The phenomenological premises for our third question: the basic phenomenological hierarchy of inclusion and complexity concerning the three varieties of medisense.

As the previously mentioned quote indicates, when working with the question one should take a special interest in the concept of attention and the perception of individual objects (abstraction related to altersense) as well as the way feelings become connected (suggestion) in an overall process “...where something not-self is set up over against the consciousness.” (CP 7.544).

\subsection{Association, similarity, contiguity, and interest}

As mentioned in the above, Peirce understood ideas as being attracted to one another by associational habits and dispositions by similarity, contiguity, and interest. Hence, now we have moved to the specific types of association as described by Peirce (and to a horizontal dimension of association). Peirce was very well acquainted with the history of theories of the association of ideas, and he frequently referred to thinkers such as Aristotle, Abelard, St. Thomas Aquinas, Locke, Hume, James Mill, and Bain, to mention but a few. Peirce himself focused on the relation between ideas believing that association is the only force that exists within the intellect. Hence, there is a regularity concerning the connection of ideas, and according to Peirce ideas are connected via 
similarity, contiguity, and interest. Association via similarity results from a power within. Peirce wrote the following about association via similarity:

It is absurd to say that different things which cannot be compared are alike, except in the sense that they act alike. Now, two ideas are compared only in the idea of the class, lot, or set to which they belong; and they act alike only in so far as they have one and the same relation to that connecting idea. Resemblance, then, is a mode of association by the inward nature of ideas and of mind. (CP 7.392)

The similarity is based on behavior and recognition of shared properties; however, the mature Peirce was an extreme realist, arguing for the reality of the three categories (see, e.g., CP 1.422, 8.208). As a consequence it is not mind that introduces the similarity. Concerning association via contiguity, Peirce wrote that it is experience that relates two ideas or it is a: “...connection due to a power without" (CP 6.105). Or put in other words: in association via contiguity there is an: “... external compulsion upon us to think things together" (W 6: 186). Therefore, in association via contiguity we are compelled to pay attention for some reason. For example, two things in proximity to each other or in a temporal sequence can become related. Finally, according to Peirce association via interest should be understood in the following way:

Another kind of association which is very important is that which makes an idea interesting. I propose to term it association by interest. An idea occurs to us in such a way that it would, other things being equal, be very dim. For example, it may result from a fortuitous putting together of two other ideas both of which are sunk deep in the subconscious mind. But if the new idea happens to be interesting, it will promptly become vivid. (CP 7.499)

An idea becomes interesting when it corresponds to the composite of ideas concerning aims, ideals, and purposes of someone; association via interest takes place when an idea is drawn into vividness by the vividness of the composite of ideas concerning aims, ideals, and purposes. After having shortly described the three types of association according to Peirce, it is time to return to the phenomenological perspective. Keeping in line with the previous argumentation, we believe that next question concerning a Peircean phenomenological description of association should involve a focus on the relationship between the concepts of similarity, contiguity, and interest. And keeping in line with the same argumentation, we will also take a look at the phenomenological status of the three concepts - meaning how they are determined by Thirdness, Secondness, and Firstness. A possible way to do that is by looking at the relationship between the types of association and Peirce's most important typology of signs - the "second sign-trichotomy" consisting of icon, index, and symbol (see CP 2.275). With respect to this relationship Peirce accentuated the following: "The association of ideas is said to proceed 
according to three principles...But it would be equally true to say that signs denote what they do" (W 2: 237). The point is that the icon, index, and symbol correspond to the three types of association. Hence, when we represent the dynamical object via the representamen and the interpretant (see, e.g., SS: 80-81) we can do that based on similarity, contiguity, and interest. In "Syllabus of Certain Topics of Logic" (c.1903) Peirce also wrote:

A regular progression of one, two, three may be remarked in the three orders of signs, Icon, Index, Symbol. The Icon has no dynamical connection with the object it represents; it simply happens that its qualities resemble those of that object, and excite analogous sensations in the mind for which it is a likeness. But it really stands unconnected with them. The index is physically connected with its object; they make an organic pair, but the interpreting mind has nothing to do with this connection, except remarking it, after it is established. The symbol is connected with its object by virtue of the idea of the symbolusing mind, without which no such connection would exist. (CP 2.299)

But then we can also deduce that similarity is determined by Firstness, contiguity is determined by Secondness, and interest is determined by Thirdness because the icon, the index, and the symbol are signs of Firstness, Secondness, and Thirdness, respectively. This puts us into a position where we can think of the three types of association in a phenomenological perspective - association by interest is a Third in the triad of types of association, and it must, therefore, directly involve contiguity and similarity indirectly - thereby association by interest must also be the highest type or the most complex type of association (see, e.g., CP 2.237). This brings us to formulate our fourth and final question concerning the phenomenological description of association: 4) How does association by interest involve and mediate between contiguity and similarity? (Figure 3).

\section{Concluding thoughts}

According to Peirce association is the only force that exists within the intellect. But how can we explore into the nature of this interesting mechanism of the intellect? Given the fact that the phenomenological categories are universal and necessary features of all experience, it makes sense to treat association as a "phenomenon" in a Peircean perspective. In the above we have tried to point towards four questions that can be the basis of a phenomenological description; and the questions themselves rest on the following premises concerning at least three triadic phenomenological relations of interdependence:

- As a variety of medisense, association must involve altersense and feeling.

- As the third variety of medisense, association must involve and mediate between abstraction and suggestion. 


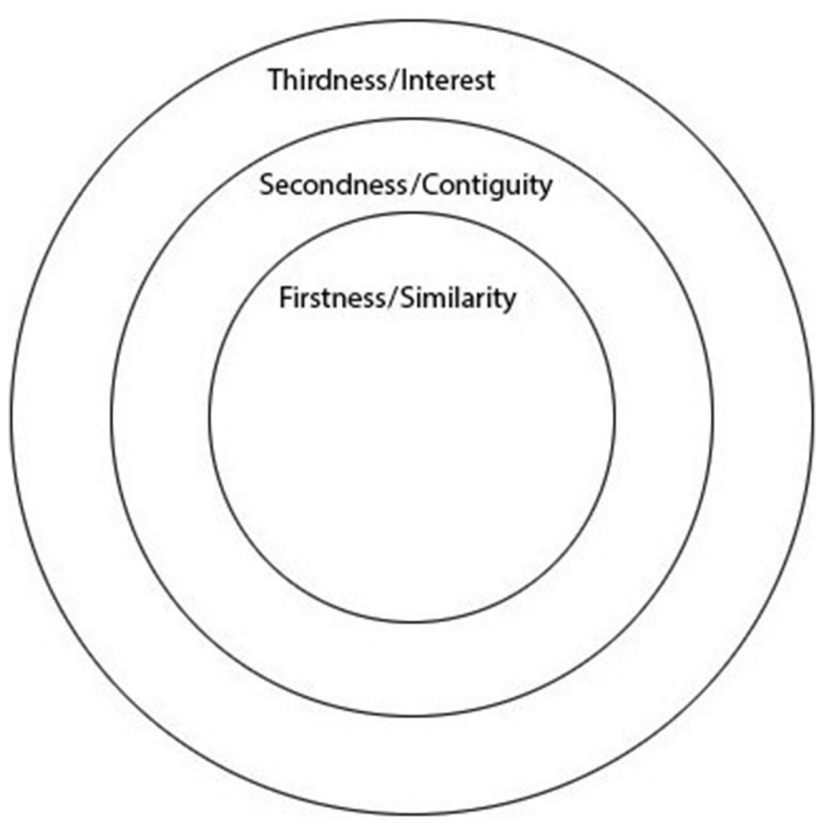

Figure 3: The phenomenological premises for our fourth question: the basic phenomenological hierarchy of inclusion and complexity concerning the three types of association.

- There are three different types of association, these types of association must - in different ways - be related to 1) and 2).

- The three different types of association are interrelated in a hierarchy, where interest is a Third, hence involving and mediating between contiguity and similarity.

Now the Peircean phenomenological work can begin to answer the following four questions:

1) As a variety of medisense, how does association "bring something to mind"? Which seems to rest upon 2) and 3):

2) In what way does association as a variety of medisense - or Thirdness - involve and mediate between altersense - or Secondness - as well as feeling - or Firstness?

3) Being a Third of medisense, how does association involve and mediate between suggestion as well as abstraction respectively?

4) How does association by interest involve and mediate between contiguity and similarity? 
Acknowledgement: For Amalia Nurmadewi.

\section{References}

Hardwick, Charles S. (ed.). 1977. Semiotics and significs: The correspondence between Charles S. Peirce and Victoria Lady Welby. Bloomington, IN: Indiana University Press. [Reference to Peirce's correspondence will be designated SS followed by page number.]

Peirce, Charles S. 1931-1966. The collected papers of Charles S. Peirce, 8 vols., C. Hartshorne, P. Weiss \& A. W. Burks (eds.). Cambridge: Harvard University Press. [Reference to Peirce's papers will be designated $C P$ followed by volume and paragraph number.]

Peirce, Charles S. 1982-. Writings of Charles S. Peirce, 8 vols., M. Fisch, E. Moore \& C. Kloesel (eds.). Bloomington: Indiana University Press. [Reference to Peirce's writings will be designated $W$ followed by volume and page number.] 